\title{
CENTRAL COMPOSITE DESIGN IN A REFINERY'S WASTEWATER TREATMENT BY AIR FLOTATION
}

\author{
F. RIGAS ${ }^{1 *}$, \\ P. PANTELEOS ${ }^{1}$ and \\ C. LAOUDIS ${ }^{2}$
}

\author{
${ }^{1}$ National Technical University of Athens \\ Department of Chemical Engineering \\ GR-15700 Athens, Greece \\ ${ }^{2}$ ECOTECH Ltd, Athens, Greece
}

* to whom all correspondence should be addressed: tel: + 30-1-7723267; fax: +30-1- 7723163

\begin{abstract}
Water resulting from the dewatering process of petroleum storage tanks was treated in a pilot separator to investigate the effectiveness of the combined action of a coagulant (aluminum sulfate) and a cationic flocculant (NALCO 71403). Central composite design of experiments was used to construct second order response surfaces for the turbidity, suspended solids and oil content as optimization parameters. The coagulant and flocculant concentrations and $\mathrm{pH}$ were used as design factors. The separator constructed for this purpose proved to be suitable for fast and reliable investigation of multivariable systems and for search of the optimum via statistical design of experiments.
\end{abstract}

KEYWORDS: Optimization, bench-scale separator, particle and oil removal, oily water.

\section{INTRODUCTION}

Many authors have stressed on the advantages of using Dissolved Air Flotation (DAF) or Induced Air Flotation (IAF) instead of the Conventional Gravity Settling (CGS). Among these are economy in space, very short hydraulic detention times and ability to handle 'mass-shock loadings' (Lavallee and Nadreau, 1997). Thus, in secondary clarifications the time needed to clarify e.g. a pulp and paper mill wastewater is about 10 min for DAF and four hours for a typical conventional gravity settler (Malley and Edzwald, 1991). DAF systems are in general more efficient than IAF due to the lower size of air bubbles obtained, thus necessitating multi-stage clarification systems, if IAF is to be used.
Flotation processes have been proven suitable to remove both suspended solids and oils at a time from a great variety of turbid waters, such as eutrophic natural water, pulp industry effluent, textile and dyeing industry, food industry, municipal wastewater, tannery process wastewater, petrochemical wastewater, oil production and refining and electroplating and battery industries (Lavallee and Nadreau, 1997; Gehr et al., 1993; Valade et al., 1996; Al-Muzaini et al., 1994).

Flotation aids for DAF and IAF are usually the normal coagulants and flocculants used in gravity settlers. When in addition surfactants are used, foam flotation can effectively remove color, turbidity, inorganics and soluble organics (Malley 
and Edzwald, 1991). Furthermore, it has been shown that after treatment of wastewater with hydrogen peroxide and ferric to precipitate out dissolved solids followed by the removal of the resulting solids by DAF, the residual COD could be reduced by $70-90 \%$ (Woollen, 1994). The type of chemical program, as well as the optimum dosage, is usually determined by laboratory jar test methods (Lavallee and Nadreau, 1997; Malley and Edzwald, 1991).

The design parameters for a flotation system include detention time, overflow rate, recycle ratio, and saturator pressure (only for DAF). To cope with such a multi-parametric system, statistical designs of experiments have been used, such as the factorial design yet only for screening significant factors (Valade et al., 1996; Woollen, 1994). Flotation processes are mainly characterized on an empirical basis, with only a few efforts to model these systems describing the basic components and the contact and separation zones (Liers et al., 1996).

In this work, the second order central composite design was used to investigate the effects of coagulant and flocculant doses and $\mathrm{pH}$ on turbidity, suspended solids and oil contents of a wastewater originating from the dewatering process of a refinery's storage tank.

\section{EXPERIMENTAL}

\section{Materials and methods}

IAF studies were performed using a bench-scale flotation system constructed for the purposes of this work and shown in Figure 1. The IAF separator is in fact a semi-cell of an industrial downscaled system which usually consists of at least three cells to obtain an over-all efficiency above $90 \%$. The volume of this laboratory separator was 1.75 1. To compensate for the one-stage treatment instead of the industrially established three stages, the detention time was kept at $50 \mathrm{~min}$, overflow rate $0.15 \mathrm{~m}^{3} \mathrm{~m}^{-2} \mathrm{~h}^{-1}$ and air to waste ratio $19 \mathrm{~m}^{3} \mathrm{~m}^{-3}$. A porous glass air disperser was used instead of the impellers used in the industry to induce air into the wastewater. This had the advantage to control the airflow at the required level. The characterization of the oily-water from dewatering the storage tanks of the refinery gave the values shown in Table 1.

Table 1. Characteristics of the wastewater treated.

\begin{tabular}{lc}
\hline Characteristics of the wastewater & Value \\
\hline Suspended Solids $\left(\mathrm{mg} \mathrm{l}^{-1}\right)$ & 165 \\
Oil $\left(\mathrm{mg} \mathrm{l}^{-1}\right)$ & 78 \\
COD $\left(\mathrm{mg} \mathrm{l}^{-1}\right)$ & 980 \\
BOD5 $\left(\mathrm{mg} \mathrm{l}^{-1}\right)$ & 150 \\
Turbidity (NTU) & 99.5 \\
pH & 7.2 \\
\hline
\end{tabular}

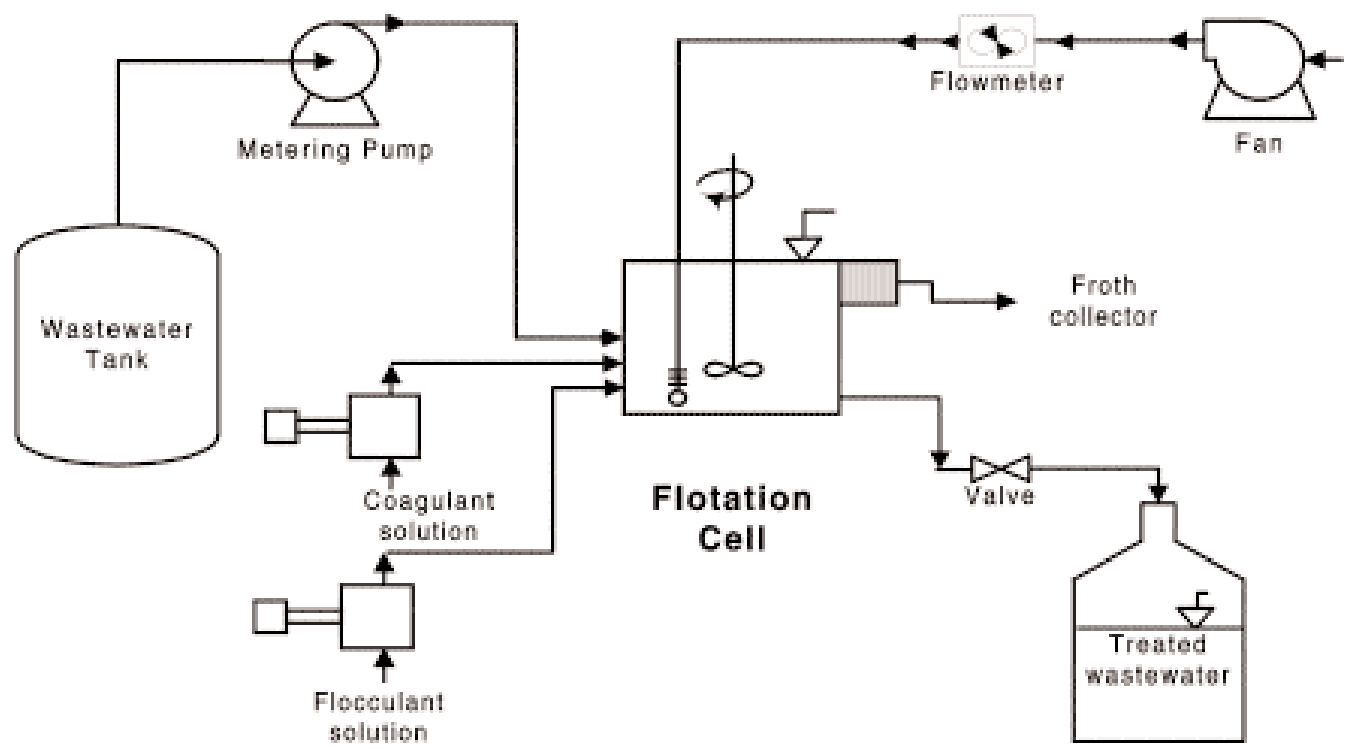

Figure 1. Simplified flow sheet of the bench-scale separator constructed. 
Table 2. Coded and natural levels of the design factors.

\begin{tabular}{lccccc}
\hline Design factors & -1.414 & -1 & 0 & +1 & +1.414 \\
\hline $\mathrm{X}_{1}:$ Aluminum Sulfate $\left(\mathrm{mg} \mathrm{l}^{-1}\right)$ & 4 & 19 & 55 & 91 & 106 \\
$\mathrm{X}_{2}:$ Polyelectrolyte $\left(\mathrm{mg} \mathrm{l}^{-1}\right)$ & 1 & 5 & 15 & 25 & 29 \\
$\mathrm{X}_{3}: \mathrm{pH}$ & 5 & 5.5 & 7 & 8.5 & 9 \\
\hline
\end{tabular}

The methods used to determine these parameters were either instrumental or according to the methods given in the 'Standard Methods' (1992). Aluminum sulfate (Technical grade, Moscholios Chemicals S.A.) was used as a coagulant and the cationic polyelectrolyte NALCO 71403 as a flocculant.

\section{Statistical Design of Experiments}

A central composite design (Biles and Swain, 1980) was applied with three design factors, namely the coagulant content (X1), the flocculant content (X2) and $\mathrm{pH}$ (X3). The coded levels and the natural values of the factors set in this statistical experiment are shown in Table 2. The selected optimization parameters were percent turbidity reduction (Y1), percent suspended solids reduc- tion (Y2) and percent oil reduction (Y3). Four replications were performed at the center point.

The design matrix of the central composite design chosen together with the results for the 3 optimization parameters selected are shown in Table 3 . The number of trials $(\mathrm{N})$ was based on the number of the design factors $(k=3)$ as follows:

$$
\mathrm{N}=2^{\mathrm{k}}+2 \mathrm{k}+4=18 \text { trials }
$$

The number of trials needed for a full second order factorial design would be instead:

$$
\mathrm{N}=3^{\mathrm{k}}+4=31 \text { trials }
$$

The decrease in the number of trials is significant and the benefit is more pronounced in the case of 6 factors, where the number of trials would be 80 and 733 for the central composite and the full second order factorial designs, respectively.

Table 3. Design matrix and results of the central composite design. The factors are expressed in coded values and those of the optimization parameters in percent reduction. Y1, Y2 and Y3 stand for percent turbidity reduction, percent suspended solids reduction and percent oil reduction, respectively.

\begin{tabular}{ccccccc}
\hline No. & $\mathbf{X 1}$ & $\mathbf{X 2}$ & $\mathbf{X 3}$ & $\mathbf{Y 1}$ & $\mathbf{Y 2}$ & $\mathbf{Y 3}$ \\
\hline 1 & 1 & 1 & 1 & 95.5 & 90.1 & 85.1 \\
2 & 1 & 1 & -1 & 68.9 & 76.7 & 13.4 \\
3 & 1 & -1 & 1 & 11.6 & 21.2 & 55.4 \\
4 & 1 & -1 & -1 & 56.8 & 50.3 & 87.3 \\
5 & -1 & 1 & 1 & 69.7 & 76.7 & 88.8 \\
6 & -1 & 1 & -1 & 55.8 & 72.1 & 40.1 \\
7 & -1 & -1 & 1 & 25.6 & 7.3 & 88.5 \\
8 & -1 & -1 & -1 & 17.6 & 27.3 & 18.5 \\
9 & 1.414 & 0 & 0 & 56.8 & 46.1 & 64.3 \\
10 & -1.414 & 0 & 0 & 52.6 & 46.7 & 78.3 \\
11 & 0 & 1.414 & 0 & 41.5 & 63 & 91.1 \\
12 & 0 & -1.414 & 0 & 17.6 & 3.1 & 28.7 \\
13 & 0 & 0 & 1.414 & 58.8 & 7.9 & 24.8 \\
14 & 0 & 0 & -1.414 & 35.7 & 6.1 & 22.3 \\
15 & 0 & 0 & 0 & 30.9 & 9.2 & 22.4 \\
16 & 0 & 0 & 0 & 28.7 & 6.9 & 20.7 \\
17 & 0 & 0 & 0 & 20.2 & 3.6 & 19 \\
18 & 0 & 0 & 0 & 25.9 & 2.3 & 18.2 \\
\hline
\end{tabular}


Table 4. Test of significance of factors and interactions after ANOVA for the models $\mathrm{Y}_{1}, \mathrm{Y}_{2}$ and $\mathrm{Y}_{3}$.

\begin{tabular}{crrrrrr}
\hline \multirow{2}{*}{$\begin{array}{c}\text { Factor or } \\
\text { interaction }\end{array}$} & \multicolumn{2}{c}{ Parameter $\mathrm{Y}_{1}$} & \multicolumn{2}{c}{ Parameter $\mathrm{Y}_{2}$} & \multicolumn{2}{c}{ Parameter $\mathrm{Y}_{3}$} \\
\cline { 2 - 7 } & $\begin{array}{c}\text { Estimated } \\
\text { effect }\end{array}$ & P-value & $\begin{array}{c}\text { Estimated } \\
\text { effect }\end{array}$ & P-value & $\begin{array}{c}\text { Estimated } \\
\text { effect }\end{array}$ & P-value \\
\hline $\mathrm{X}_{1}$ & 5.84 & 0.0222 & 4.50 & 0.0156 & -1.21 & 0.4668 \\
$\mathrm{X}_{2}$ & 17.67 & 0.0009 & 24.52 & 0.0001 & 5.50 & 0.0324 \\
$\mathrm{X}_{3}$ & 3.00 & 0.1105 & -2.38 & 0.0784 & 13.50 & 0.0026 \\
$\mathrm{X}_{1}{ }^{2}$ & 13.35 & 0.0038 & 24.53 & 0.0002 & 23.05 & 0.0010 \\
$\mathrm{X}_{1}{ }^{*} \mathrm{X}_{2}$ & 1.71 & 0.3721 & -2.36 & 0.1229 & -8.26 & 0.0189 \\
$\mathrm{X}_{1}{ }^{*} \mathrm{X}_{3}$ & -5.06 & 0.0535 & -0.037 & 0.9751 & -9.86 & 0.0116 \\
$\mathrm{X}_{2}{ }^{2}$ & 0.78 & 0.6664 & 17.85 & 0.0005 & 17.35 & 0.0023 \\
$\mathrm{X}^{2 *} \mathrm{X}_{3}$ & 9.71 & 0.0096 & 8.39 & 0.0048 & 10.29 & 0.0103 \\
$\mathrm{X}_{3}{ }^{2}$ & 9.63 & 0.0098 & 4.83 & 0.0224 & -0.83 & 0.6731 \\
\hline
\end{tabular}

Table 5. Lack-of-fit, R-squared and Durbin-Watson statistics for the constructed models after ANOVA.

\begin{tabular}{ccccccc} 
& \multicolumn{2}{c}{ P-value for lack-of-fit } & \multicolumn{2}{c}{ R-squared test } & \multicolumn{2}{c}{ Durbin-Watson statistic } \\
\hline $\begin{array}{c}\text { All factors } \\
\text { included }\end{array}$ & $\begin{array}{c}\text { Insignificant } \\
\text { factors } \\
\text { excluded }\end{array}$ & $\begin{array}{c}\text { All factors } \\
\text { included }\end{array}$ & $\begin{array}{c}\text { Insignificant } \\
\text { factors } \\
\text { excluded }\end{array}$ & $\begin{array}{c}\text { All factors } \\
\text { included }\end{array}$ & $\begin{array}{c}\text { Insignificant } \\
\text { factors } \\
\text { excluded }\end{array}$ \\
\hline $\mathrm{Y}_{1}$ & 0.032 & 0.051 & 84.1 & 80.2 & 2.01 & 2.23 \\
$\mathrm{Y}_{2}$ & 0.036 & 0.052 & 96.4 & 95.7 & 1.36 & 1.35 \\
$\mathrm{Y}_{3}$ & 0.007 & 0.011 & 70.3 & 70.2 & 2.58 & 2.59 \\
\hline
\end{tabular}

Comparing the mean square against an estimate of the experimental error tested the statistical significance of factors and their interactions. Then, the effects having $p$-values less than 0.05 , indicating that these were significantly different from zero at the $95 \%$ confidence level, were discarded. The lack-of-fit test was used to determine whether the constructed models were adequate to describe the observed data. The test is performed by comparing the variability of the current model residuals to the variability between observations at replicate settings of the factors. When the estimated p-value for the lack-of-fit is less than 0.05 , there is statistically significant lack-of-fit at the 95\% confidence level. That means that the model does not adequately represent the data.

The $R$-squared statistic indicates the percentage of the variability of the optimization parameter that is explained by the model.

The Durbin-Watson (DW) statistic tests the residuals to determine, if there is any significant correlation based on the order in which they occur in the data file. When the DW value is greater than
1.4, there is probably not any serious autocorrelation in the residuals.

The computations were performed with the aid of Statgraphics software. The Surfer software plotted the figures.

\section{RESULTS}

The results obtained after running the 18 trials of the statistical design and the design matrix are shown in Table 3. The estimated values of the factors coefficients and their interactions are shown in Table 4, together with their p-values. The effects with p-values higher than 0.05 are insignificant at the $95 \%$ confidence level and were discarded. The Analysis of Variance (ANOVA) for the tests of adequacy of the models is shown in Table 5 for the case of all factors inclusion as well as the case of insignificant factors exclusion.

\section{DISCUSSION}

The lack-of-fit statistic, used to test the adequacy of the models obtained, demonstrate that considerable improvement was achieved after the exclu- 
sion of the statistically insignificant effects. Nevertheless, the model for oil reduction $\left(\mathrm{Y}_{3}\right)$ remains inadequate to describe the observed data in spite of the improvement of its p-value. This is verified also by the low R-squared value indicating the percentage of the variability of $Y_{3}$ that is explained by the model. Since it is not possible to obtain a new sample identical with that used in this experimental design from the same or other industrial source, the only way is to proceed to the evaluation of the $Y_{3}$ model obtained, yet with reservations about conclusions that may differ greatly from those achieved from the other two models.

The Durbin-Watson (DW) statistic values obtained show that there might be some serial correlation based on the order in which they occur in the data file only for the $\mathrm{Y}_{2}$ model. Yet, the DW value for this model is only slightly lower (1.35) than the critical value of this statistic (1.4). Furthermore, plotting of the residuals versus row order showed that there is no pattern that could be seen.

Finally, the models (response surfaces) resulting after running the 18 trials and discarding the insignificant effects are the following:

$$
\begin{aligned}
Y_{1} & =27.5+5.84 * X_{1}+17.7 * X_{2}+13.4 * X_{1}^{2}+ \\
& +9.71 * X_{2} * X_{3}+9.63 * X_{3}^{2}
\end{aligned}
$$

Since all these are second order models, they do not show straightaway the dependence of the optimization parameters on the design factors. To accomplish this, the contour lines of the response surfaces were plotted in Figures 2-4 keeping each time the missing factor at its center level.

It is deduced from Fig. 2 that turbidity depends strongly on polyelectrolyte dose and slightly on $\mathrm{pH}$ and aluminum sulfate dose. For both, $\mathrm{pH}$ and aluminum sulfate, turbidity reduction passes by a minimum at about $27 \%$ turbidity reduction at the coded point $(-0.2,0,0)$, whereas a local maximum of about $64 \%$ turbidity reduction is found at the coded point $(+1,+1,0)$. The turbidity reduction is also increased attaining $53 \%$ at the point $(-1$, $+1,0)$.

$$
\begin{aligned}
Y_{2}= & 2.78+4.50 * X_{1}+24.5 * X_{2}+24.5 * X_{1}^{2}+ \\
& +17.9 * X_{2}^{2}+8.39 * X_{2} * X_{3}+4.83 * X_{3}^{2}
\end{aligned}
$$

$$
\begin{aligned}
Y_{3} & =21.2+5.50 * X_{2}+13.5 * X_{3}+23.0 * X_{1}^{2}- \\
& -8.26 * X_{1} * X_{2}-9.86 * X_{1} * X_{3}+17.3 * X_{2}^{2}+ \\
& +10.3 * X_{2} * X_{3}
\end{aligned}
$$

Figure 3 shows that for total suspended solids there is a minimum of the solids reduction at the center levels of $\mathrm{pH}$ and aluminum sulfate. Again, as in the previous case, this reduction increases strongly with polyectrolyte content. The influence of $\mathrm{pH}$ is very weak, whereas aluminum sulfate affects this optimization parameter in a lesser degree than polyectrolyte. A local maximum of $74 \%$ solids reduction is found at the coded point $(+1,+1,0)$. A high value is also obtained at the point $(-1,+1,0)$, namely $65 \%$ of suspended solids reduction.

The oil reduction is minimized at the point $(0$, $-0.2,0)$ in Figure 4 (Plot A). A local maximum equal to $75 \%$ is obtained at the coded point $(-1$, $+1,0)$, whereas the high value obtained at the point $(+1,-1,0)$ is $64 \%$. The effects of polyectrolyte and aluminum sulfate doses are very close to each other, whereas $\mathrm{pH}$ significantly affects this optimization parameter.

Neglecting $\mathrm{pH}$ which is a costly matter to change it significantly in the industry, we observe that higher reduction rates for turbidity and TSS can in general be obtained at high polyelectrolyte doses (20-30 $\left.\mathrm{mg} \mathrm{l}^{-1}\right)$ and either high or low aluminum sulfate doses (90-100 or 10-20 $\mathrm{mg} \mathrm{l}^{-1}$ ). So, it seems reasonable for turbidity and TSS to select as an optimal area that of the coded point $(+1$, $+1,0$ ), where the local maxima are obtained.

Nevertheless, from the economical point of view polyelectrolytes are an order of magnitude more expensive than aluminum sulfate. On the other hand the crucial factor in oily water is its oil content. In this case two regions of local maxima are found in Figure 4 (Plot A) with regard to polyelectrolyte and aluminum sulfate, the one at high polyelectrolyte - low alum doses and the other at low polyelectrolyte - high alum doses. In the latter case the local optimum for the oil reduction is $64 \%$ at the point $(+1,-1,0)$. This result is high enough and cost effective because the expensive polyelectrolyte is found at its low level (-1).

The reductions in the levels of optimization parameters obtained are very high for a one-stage flotation system, and they may be attributed to the high detention time and the low overflow rate 
Pot A

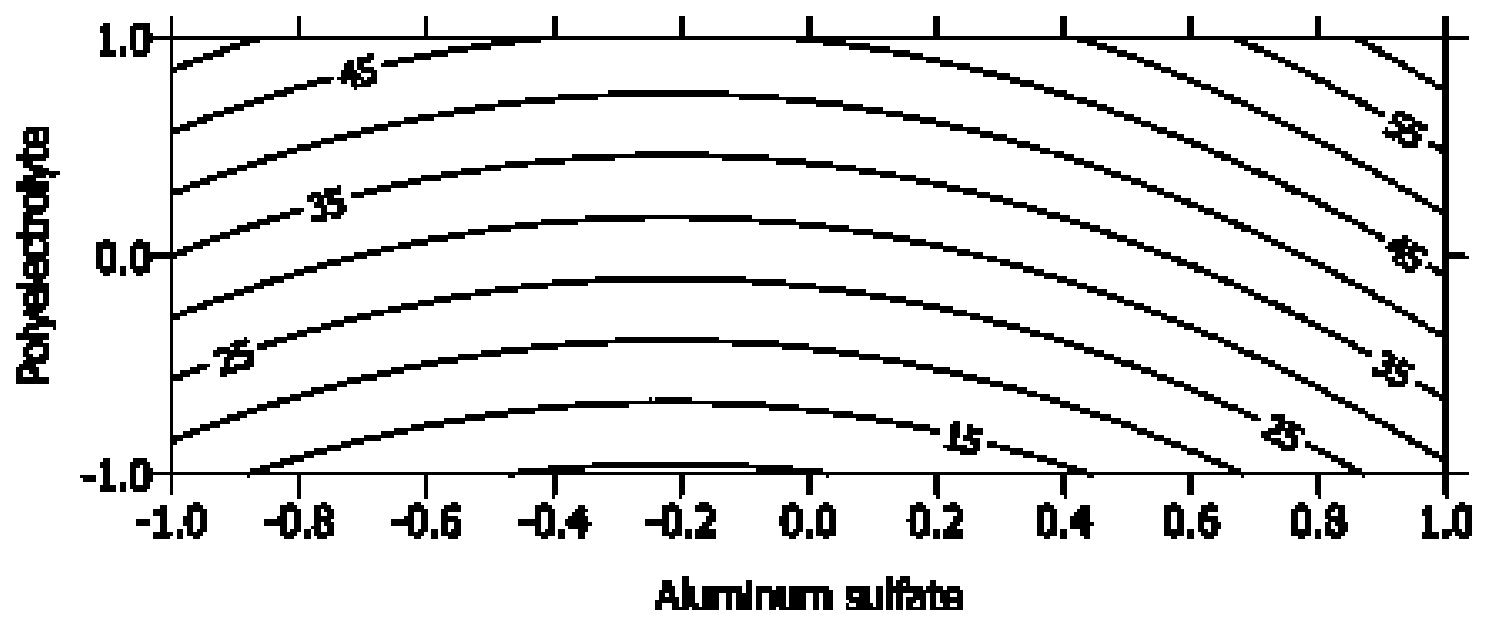

Pot B

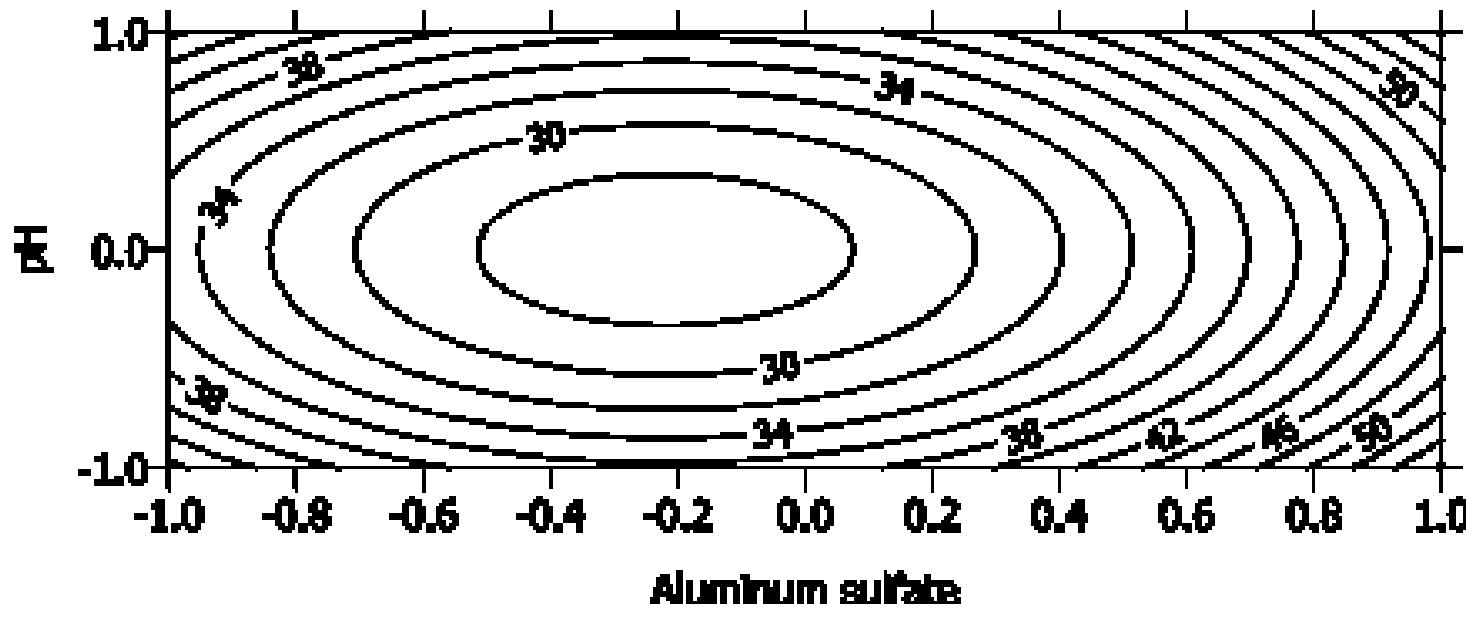

Fitc $\mathrm{C}$

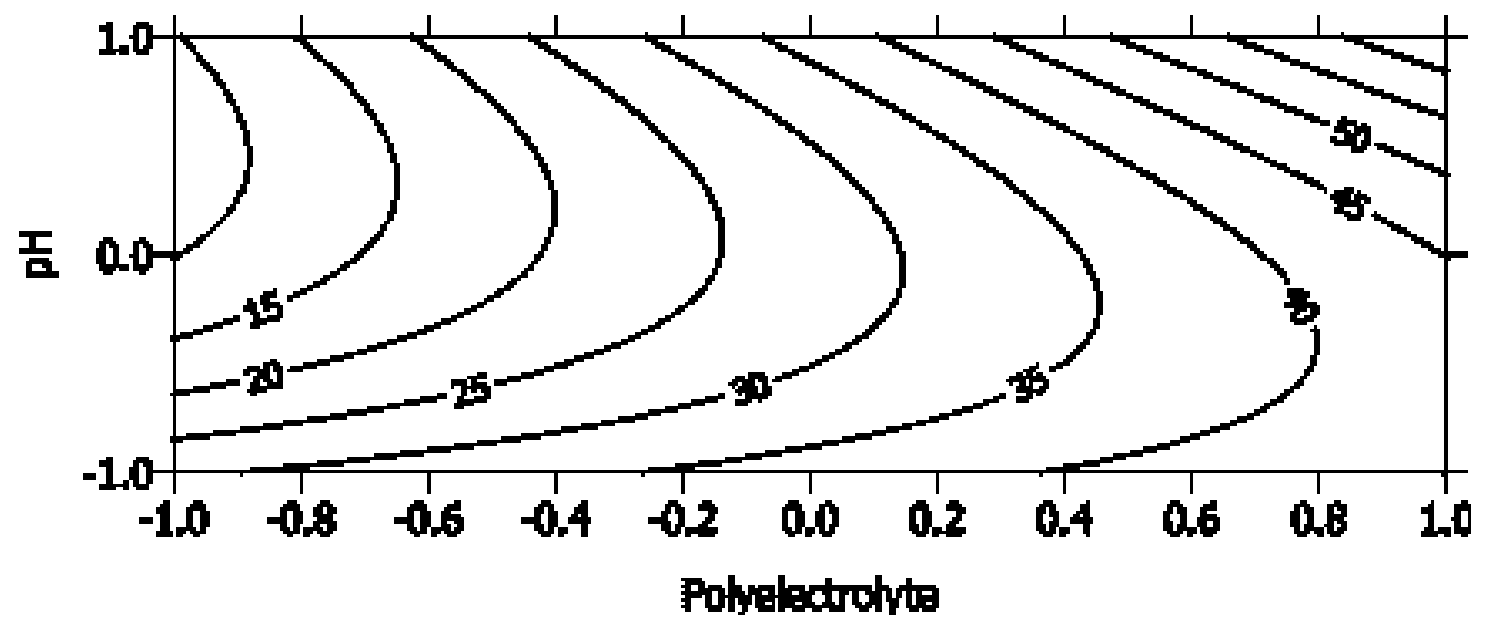

Figure 2. Dependence of turbidity (NTU) on polyelectrolyte dose, aluminum sulfate dose and pH in coded values. Response levels of percent turbidity reduction (\%) are shown as contour lines. 
Plot A

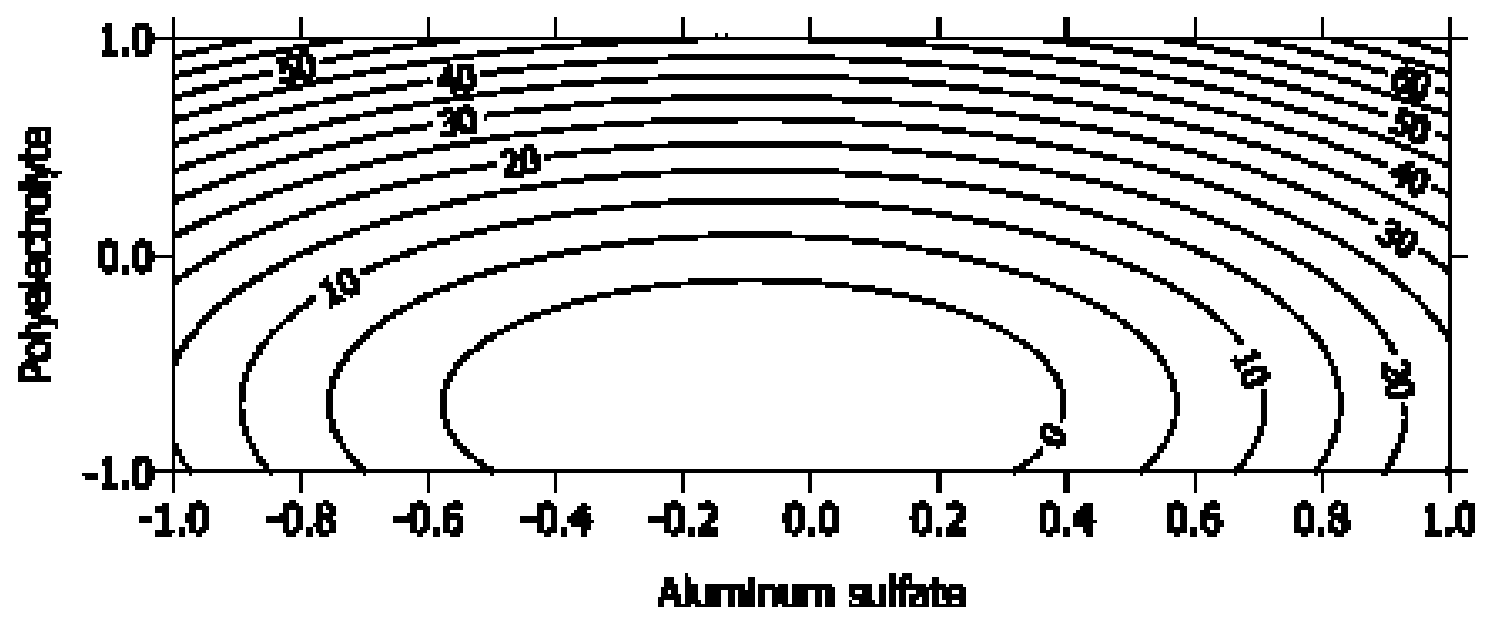

Pot B

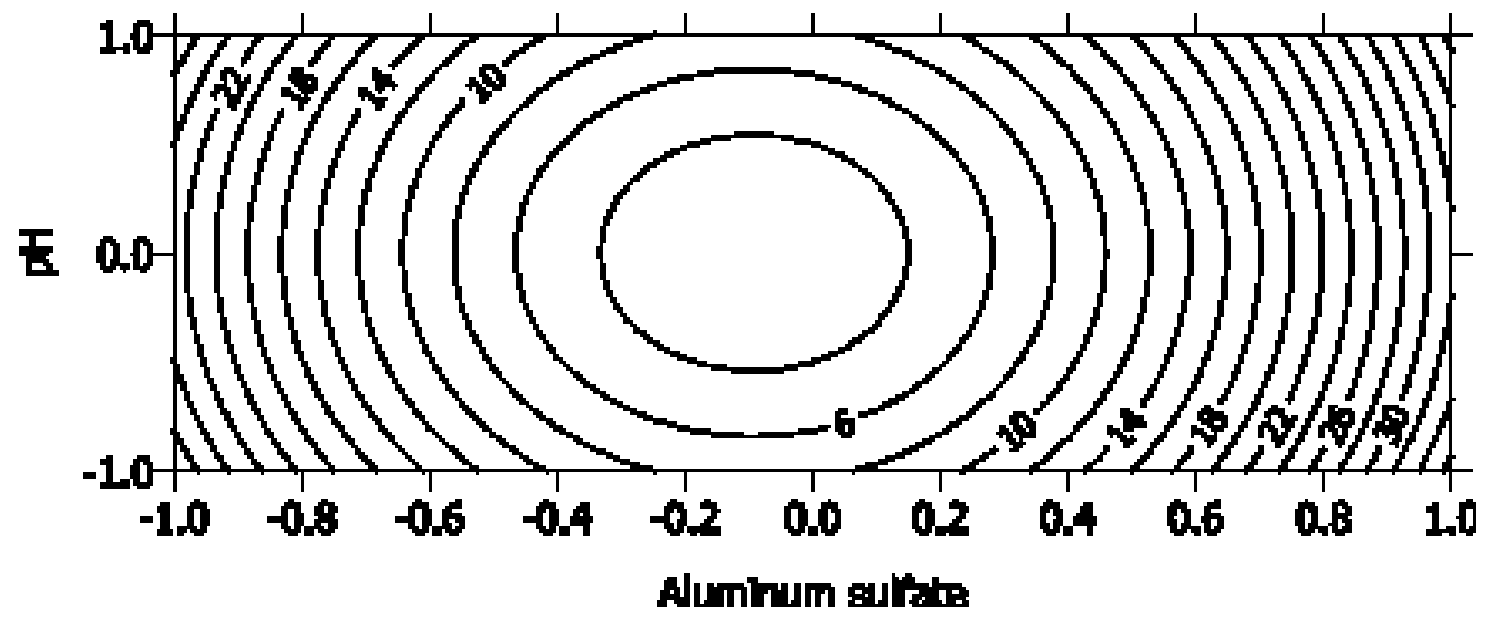

Fot C

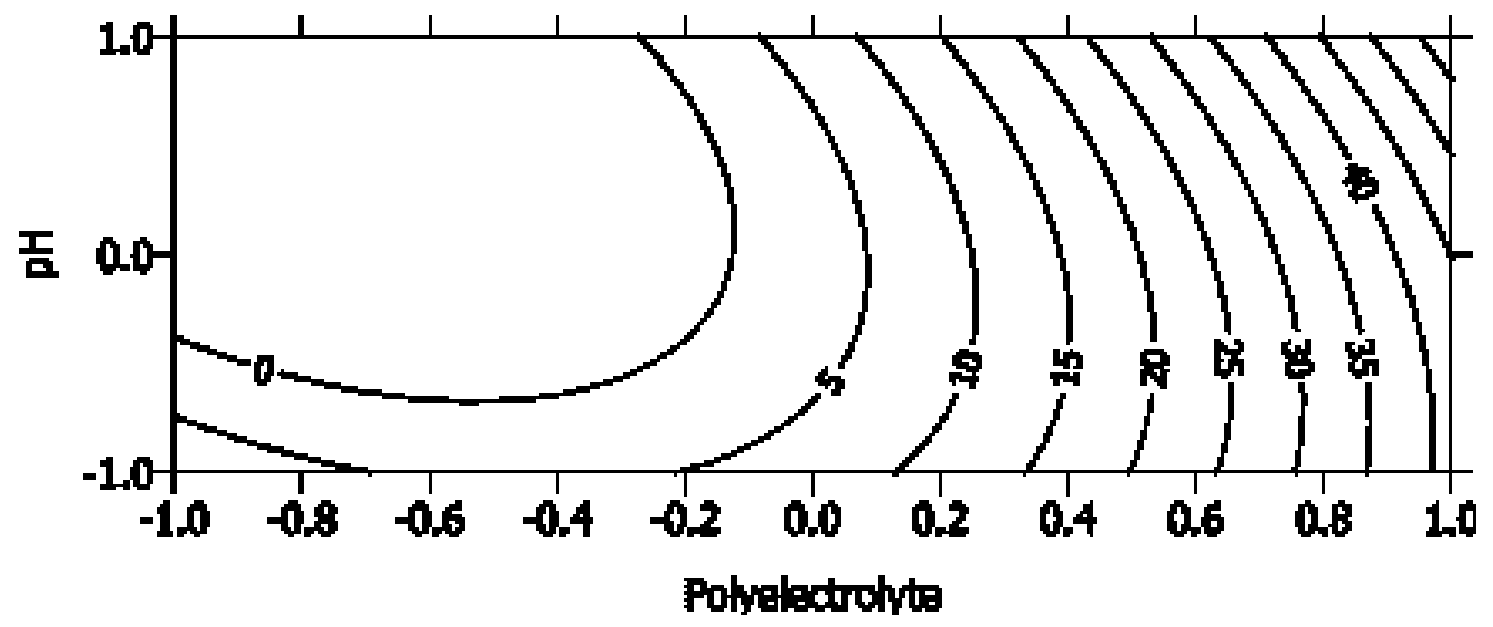

Figure 3. Dependence of total suspended solids on polyelectrolyte dose, aluminum sulfate dose and $\mathrm{pH}$ in coded values. Response levels of percent total suspended solids reduction (\%) are shown as contour lines 
Pot A

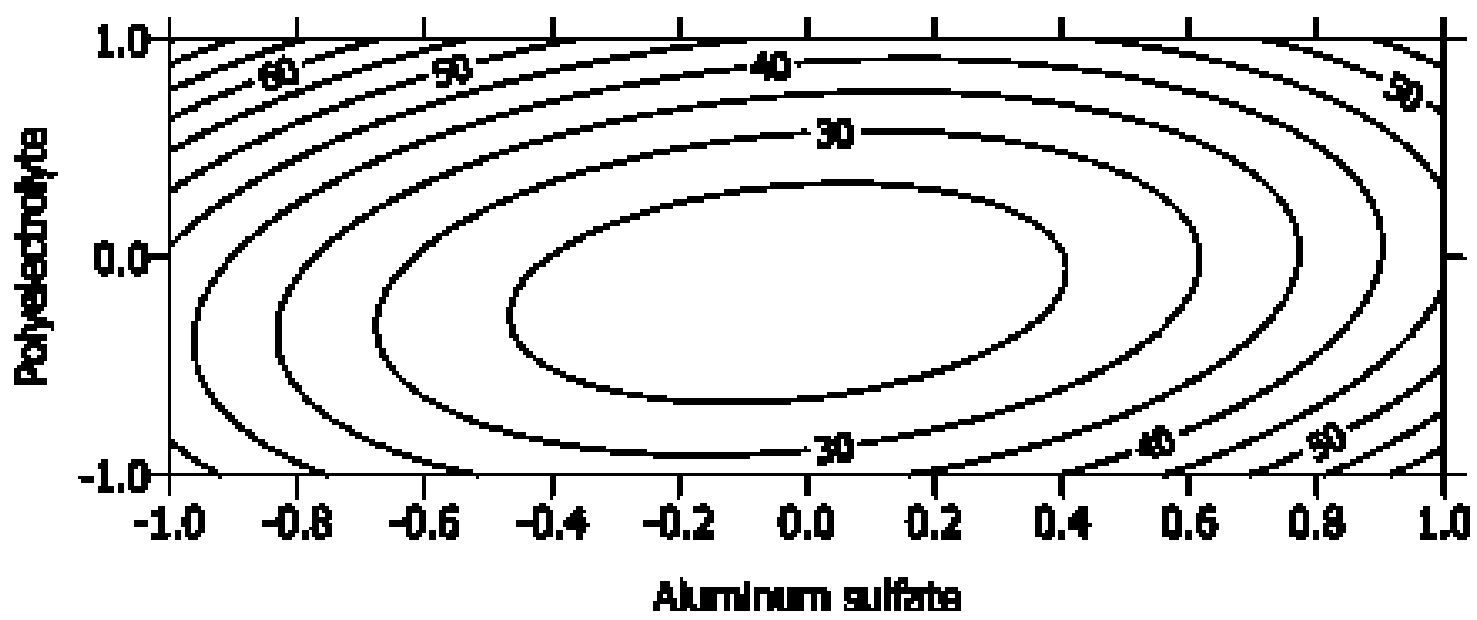

Plat B

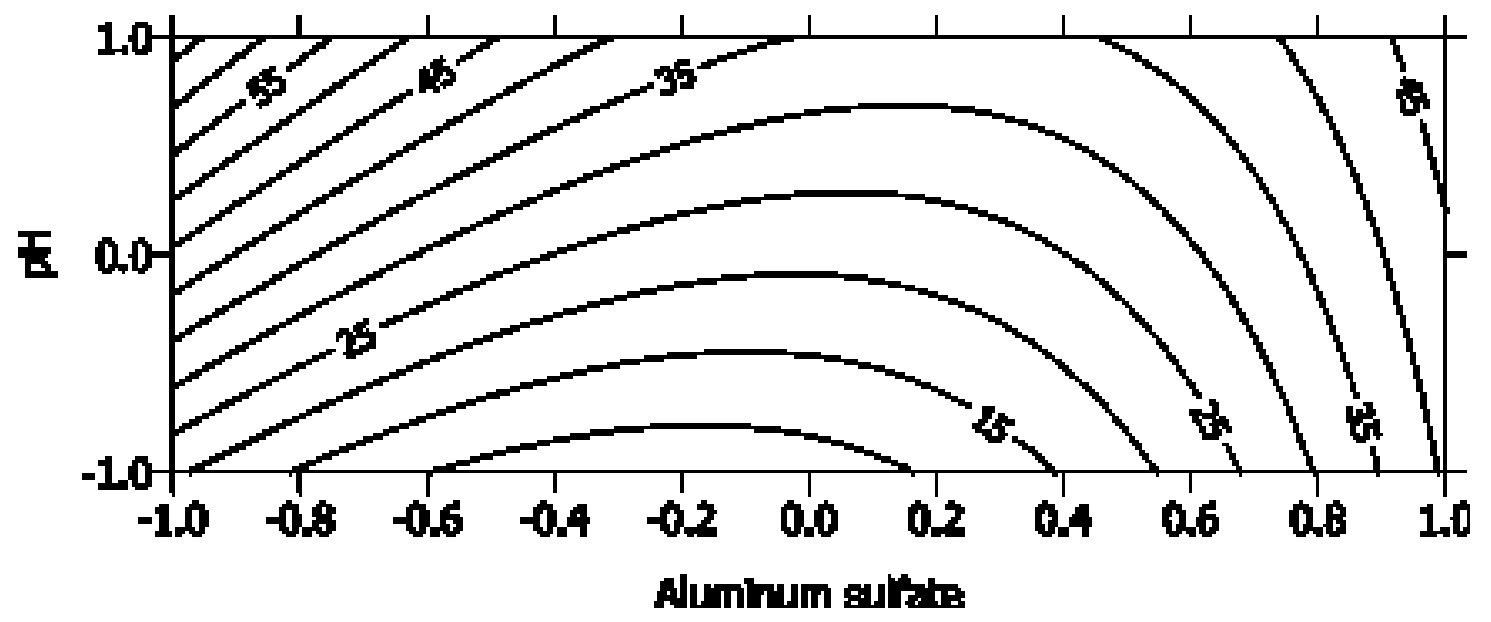

Plat C

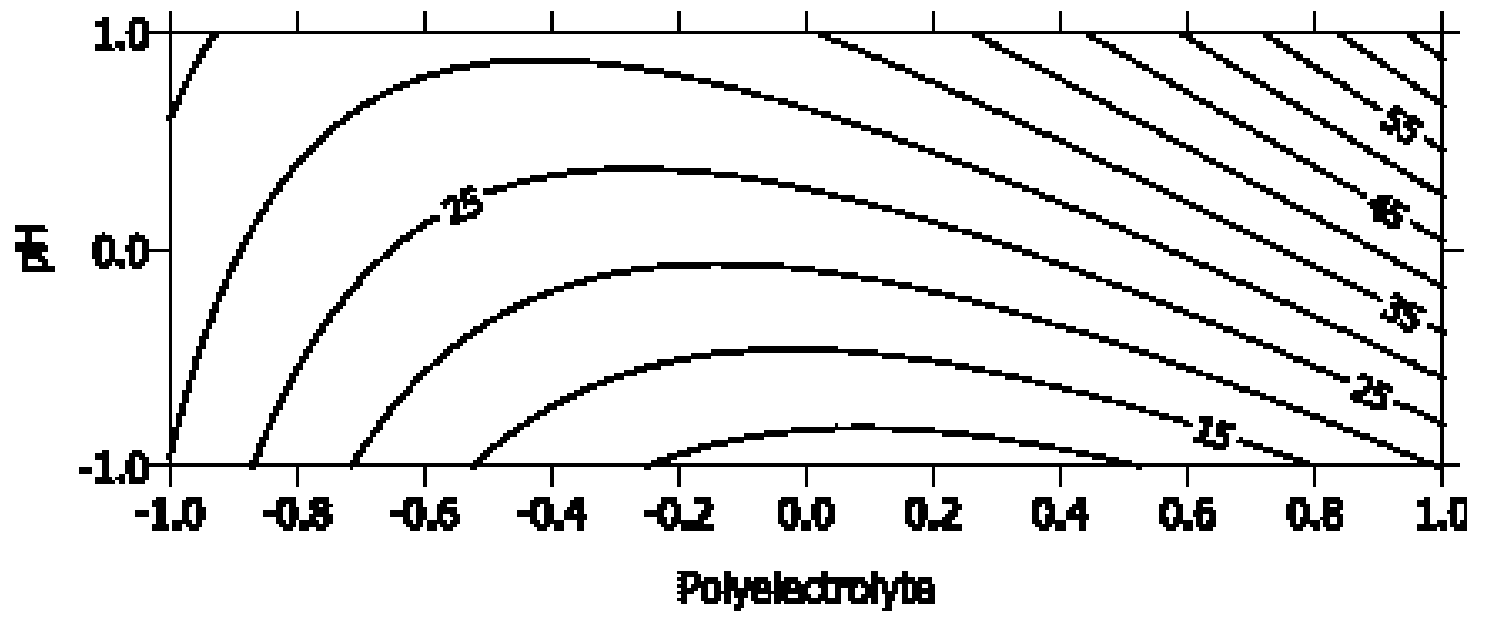

Figure 4. Dependence of oil content on polyelectrolyte dose, aluminum sulfate dose and $\mathrm{pH}$ in coded values. Response levels of percent oil content reduction (\%) are shown as contour lines. 
selected in order to visualize the influence of the design factors. In any case the flotation system constructed and the search method used (central composite design) proved suitable to investigate multi-variable effects with a minimum of trials. Taking into account the effectiveness of the search method, certain additional design factors (such as detention time, overflow rate and recycle ratio) could be included in a new search for the optimum, if an industrial application would not be satisfactory.

Scaling-up to a full size separator will not necessarily give the same results, but it would certainly be useful in the sense that the region of optimum has been located. Thus, a few additional trials in the optimal region found will be needed to identify these results.

\section{CONCLUSIONS}

The simple one-stage air flotation system constructed combined with the central composite design of experiments, proved to be effective for studying the multi-variable effects of flotation and determining chemical doses.

For the optimization parameters selected (turbidity, total suspended solids and oil content reductions) optimal regions were found inside the variation intervals of the design factors. Further investigation of the system directs to higher alum and lower polyelectrolyte doses, provided the obtained results would not be satisfactory in an eventual industrial application.

The effectiveness of the search method used offers the possibility to include some additional design factors in a new search for the optimum.

\section{REFERENCES}

Al-Muzaini, S., Khordagui, H. and Hamouda, M.F. (1994), Removal of VOCs from refinery and petrochemichals wastewaters using dissolved air flotation, Water Science Technology, 30, 79-90.

Biles, W.E. and Swain, J.J. (1980), Optimization and Industrial Experimentation, Wiley-Interscience Publ., New York.

Gehr, R., Swartz, C. and Offringa, G. (1993), Removal of triahalomethane precursors from eutrophic water by dissolved air flotation, Water Resources, 27, 41-49.

Lavallee, H.C. and Nadreau, J. (1997), Dissodied Air Flotation System use increases for secondary clarification, Pulp \& Paper, 71, 99-101.

Liers, S., Baeyens, J. and Mochtar, I. (1996), Modeling dissolved air flotation, Water Environment Research, 68, 1061-1075.

Malley Jr., J.P. and Edwald, J.K. (1991), Laboraty comparison of DAF with conventional treatment, Journal $A W W A$, Sept. 1991, 56-61.

Standard Methods for the Examination of water and wastewater, APHA, AWWA, WEF, 18 ${ }^{\text {th }}$ ed., 1992.

Valade, M.T., Edzwald, J.K., Tobiason, J.E., Dahlquist, J., Hedberg, T. and Amato, T. (1996), Particle removal by flotation: pretreatment effects, Journal AWWA, Dec. 1996, 35-47.

Woollen, P.S. (1994), Reusing tertiary effluent after treatment with a DAF and sandfilter system, Paper technology, July/August 1994, 18-20. 